\title{
Production of the Pseudomonas aeruginosa Neuraminidase Is Increased under Hyperosmolar Conditions and Is Regulated by Genes Involved in Alginate Expression
}

Grace Cacalano, Maureen Kays, Lisa Saiman, and Alice Prince

Division of Infectious Diseases, Department of Pediatrics, College of Physicians and Surgeons, Columbia University, New York 10032

\begin{abstract}
The pathogenesis of Pseudomonas aeruginosa infection in cystic fibrosis (CF) is a complex process attributed to specific characteristics of both the host and the infecting organism. In this study, the properties of the PAO1 neuraminidase were examined to determine its potential role in facilitating Pseudomonas colonization of the respiratory epithelium. The PAO1 neuraminidase was $\mathbf{1 0 0 0}$-fold more active than the Clostridium perfringens enzyme in releasing sialic acid from respiratory epithelial cells. This effect correlated with increased adherence of PAO1 to epithelial cells after exposure to PAO1 neuraminidase and was consistent with in vitro studies demonstrating Pseudomonas adherence to asialoganglioside receptors. The regulation of the neuraminidase gene nanA was examined in Pseudomonas and as cloned and expressed in Escherichia coli. In hyperosmolar conditions neuraminidase expression was increased by $50 \%(P<0.0004)$, an effect which was OmpR dependent in $E$. coli. In Pseudomonas the osmotic regulation of neuraminidase production was dependent upon algR1 and algR2, genes involved in the transcriptional activation of algD, which is responsible for the mucoid phenotype of Pseudomonas and pathognomonic for chronic infection in CF. Under the hyperosmolar conditions postulated to exist in the CF lung, nan $A$ is likely to be expressed to facilitate the initial adherence of Pseudomonas to the respiratory tract. (J. Clin. Invest. 1992. 89:1866-1874.) Key words: cystic fibrosis - neuraminidase • Pseudomonas aeruginosa
\end{abstract}

\section{Introduction}

Pseudomonas aeruginosa is a common human pathogen which is particularly important as a cause of respiratory disease in patients with cystic fibrosis (CF). ${ }^{1}$ The molecular basis for the unusual association of Pseudomonas and the CF lung is unknown, but is likely to involve the expression of one or more of the many exoproducts and/or virulence factors produced by Pseudomonas. Among the Pseudomonas virulence factors are several enzymes which modify eukaryotic proteins and matrix components (1), such as alkaline protease $(2)$, elastase $(3,4)$, the ADP ribosylating enzymes, exotoxins $A(5)$ and $S(6)$, and

Address reprint requests to Dr. Prince, Division of Infectious Diseases, Department of Pediatrics, College of Physicians \& Surgeons, Columbia University, 650 West 168th Street, New York, NY 10032.

Received for publication 4 November 1991.

1. Abbreviations used in this paper: $C F$, cystic fibrosis; IEF, isoelectric focusing.

J. Clin. Invest.

(c) The American Society for Clinical Investigation, Inc.

$0021-9738 / 92 / 06 / 1866 / 09 \quad \$ 2.00$

Volume 89, June 1992, 1866-1874 the phospholipases, PLC-H (hemolytic) and PLC-N (nonhemolytic) (7). These exoproducts can have a direct toxic effect on host tissue or may interfere with host immunologic defense mechanisms. The production of the antiphagocytic exopolysaccharide, alginate, is a distinctive Pseudomonas phenotype pathognomonic for the mucoid Pseudomonas strains associated with the chronic infection of the CF lung (8). The genes that regulate alginate production can be activated by high osmolarity (9) or dehydration (10), environmental conditions present in CF owing to diminished chloride, and consequently water transport $(11,12)$ across the epithelial surface.

The $P$. aeruginosa strains that initiate infection in the $\mathrm{CF}$ patient have less obvious phenotypes than the grossly mucoid strains. Serological studies have demonstrated that antibodies to specific Pseudomonas exoproducts are present well before organisms can be recovered from cultures of the sputum or nasopharynx (13), suggesting a role for the in vivo production of exoproducts very early in the colonization process. However, the specific gene products required for colonization of the human epithelium have not been defined, nor is it clear why this colonization process is so specific to the $\mathrm{CF}$, but not the normal respiratory tract.

Intact epithelial cells are relatively resistant to Pseudomonas attachment. Bacterial binding can be substantially increased by modification of the epithelial surface by acid (14), trypsin (15), influenza infection, trauma (16), or the effect of the accumulated $P$. aeruginosa exoproducts in culture supernatants (17). The GalNAc $\beta 1-4 \mathrm{Gal}$ sequence present in asialylated gangliosides can function as a receptor for several pathogens of the respiratory tract including $P$. aeruginosa (18). A potential role for bacterial exoproducts, particularly a neuraminidase, would be to expose sequestered binding sites within the usually sialylated membrane glycolipids and facilitate attachment to the epithelial surface.

Although the role of neuraminidase in the pathogenesis of infection has not been clearly defined, these enzymes have long been postulated to facilitate interactions between prokaryotes and mammalian hosts (19). Commensal flora such as capnophilic bacteria and anaerobes (20), streptococcal species (21), as well as pathogens such as Streptococcus pneumoniae $(22,23)$ and Vibrio cholerae (24), express these enzymes. $P$. aeruginosa was first noted to produce neuraminidase by Shilo (25). Leprat and Michel-Briand (26) further characterized the neuraminidase produced by a clinical strain of $P$. aeruginosa isolated from a child with cystic fibrosis and suggested a role for the enzyme in the pathogenesis of infection. Unlike Escherichia coli, which can metabolize the free sialic acid generated by the action of neuraminidases (27), P. aeruginosa can utilize only a limited number of carbohydrate substrates and must have another function for the production of neuraminidase.

In the studies described the biochemical properties of the neuraminidase produced by $P$. aeruginosa PAO1 were deter- 
mined, and the effect of this enzyme on human respiratory epithelial cells was examined. The environmental conditions optimal for the expression of the neuraminidase structural gene, nanA, were defined and the involvement of several central regulatory genes examined. Neuraminidase production was found to be increased under hyperosmolar conditions. This effect was dependent upon the response regulators AlgR 1 or $\mathrm{OmpR}$, suggesting that neuraminidase, like alginate, may be specifically expressed under the conditions expected to be present in the CF lung.

\section{Methods}

\section{Bacterial strains and plasmids}

P. aeruginosa PAO1 $\mathrm{H} 103$ and a PAO1 genomic library cloned in the cosmid vector pLAFR were generously provided by R. E. W. Hancock (University of British Columbia, Vancouver, BC). PAK and PAK N1, an isogenic $\mathrm{RpoN}^{-}$mutant constructed by insertion of $\mathrm{Tc}^{\mathrm{R}}$ cartridge (28), were obtained from S. Lory (University of Washington, Seattle); PA103 and PA103-29, a ToxR $R^{-}$mutant (29), were obtained from B. Iglewski (University of Rochester, Rochester, NY); P. aeruginosa 8830, a stable constitutive mucoid strain, $8852($ algR 1$)$ and $8882($ algR2) (30) were obtained from A. Chakrabarty (University of Illinois, Chicago). The $E$. coli strains used included LE392, a neuraminidase-negative host and LE392pCVD364 containing the cloned $V$. cholerae nanH gene (31) obtained from E. Vimr (University of Illinois, ChampaignUrbana). $\mathrm{MC} 4100\left(\mathrm{Nal}^{\mathrm{R}}\right.$ recA $\mathrm{F}^{-}$araD139, $\Delta($ agrF-lac) $\mathrm{U} 169$ rpsL 150 relA1 fibB25 ptsF25 deo-1), MH225.101 [MC4100\$(ompC'-lac $\left.{ }^{+}\right) 10$ $25 o m p R 101]$ and pFR29 which contains $o m p R / e n v Z$ cloned on pBR322 (32) were obtained from T. Silhavy (Princeton University, Princeton, $\mathrm{NJ})$.

\section{Culture conditions}

The $E$. coli strains were grown in L-broth (33) with tetracycline 30 $\mu \mathrm{g} / \mathrm{ml}$. All chemicals were purchased from Sigma Chemical Co., St. Louis, MO, unless otherwise specified. The $P$. aeruginosa strains were grown with aeration at $37^{\circ} \mathrm{C}$ in $\mathrm{M} 9$ media containing $10 \mu \mathrm{g} / \mathrm{ml} \mathrm{FeCl}_{2}$ unless otherwise indicated. PAK N1 was supplemented with $0.2 \%$ glutamine. For nitrogen regulation studies media containing $\mathrm{K}_{2} \mathrm{HPO}_{4}$ (10.5 g/liter), $\mathrm{KH}_{2} \mathrm{PO}_{4}\left(4.5 \mathrm{~g} /\right.$ /iter), $10 \mathrm{mM} \mathrm{MgSO}_{4}, 35 \mathrm{mM}$ sodium citrate, $0.002 \%$ thiamine, $0.02 \mathrm{mM}$ arginine, $0.2 \mathrm{mM}$ uracil, $0.2 \mathrm{mM}$ hypoxanthine was used, supplemented with $0.2 \%$ glutamine (high $\mathrm{N}_{2}$ ) or $0.01 \%$ glutamine for conditions of nitrogen limitation. Desferroxylated M9 media was prepared using plastic containers and flasks with $0.05 \mu \mathrm{g} / \mathrm{ml} \mathrm{FeCl}_{2}$ (low iron) or $10 \mu \mathrm{g} / \mathrm{ml} \mathrm{FeCl}_{2}$ (high iron) (34).

Pseudomonas culture supernatants were prepared from cultures grown to log-phase $\mathrm{OD}_{600} 0.8$ and harvested by centrifugation at 7,000 rpm (model RC5C, DuPont-Sorvall, Newtown, CT) for $10 \mathrm{~min}$ at $4^{\circ} \mathrm{C}$ in a model SS34 rotor (DuPont-Sorvall). For cultures grown in high salt the cultures were standardized by colony-forming units (CFU) per milliliter. The supernatants were sterilized by the addition of gentamicin $40 \mu \mathrm{g} / \mathrm{ml}$ and concentrated 20 -fold with polyethylene glycol (mol wt $20,000)$ at $4^{\circ} \mathrm{C}$ in dialysis tubing.

\section{Neuraminidase assays}

To quantify neuraminidase activity from Pseudomonas culture supernatants, the exoproducts obtained above were further concentrated and desalted by extensive dialysis vs. $70 \mathrm{mM} \mathrm{NaPO}_{4}$ buffer, pH 6.3. Neuraminidase activity was measured using a modification of the technique of Meyers et al. (35). The fluorogenic substrate 2'-(4-methylumbelliferyl)- $\alpha$-D- $N$-acetylneuraminic acid (MUNeuNAc) was added to a final concentration of $25 \mu \mathrm{M}(4 \mu \mathrm{l}$ of a $1.25 \mathrm{mM}$ solution in $50 \mathrm{mM}$ $\mathrm{NaAc} \mathrm{pH} 4.9)$ to one of duplicate wells of a 96-well microtiter plate containing $200 \mu \mathrm{l}$ per well. Fluorescence $(\Delta F)$ was measured in a Titertek Fluoroskan II (Flow Laboratories, Inc., McLean, VA) correcting for background fluorescence from the control wells without substrate. Ac- tivity from LE392pCVD364 was used as the positive control. The specific activity was determined as the $\Delta F$ per milligram of protein. Protein concentration was measured using a commercially obtained kit (Bio-Rad Laboratories, Richmond, CA) based on the method of Bradford (36). Hydrolysis of MUNeuNAc was shown to be linear for the range of protein concentrations used for these determinations. All assays were performed in duplicate.

The neuraminidase activity of $E$. coli strains was determined by measuring the $\Delta F$ per milligram of protein from cell extracts using MUNeuNAc as a substrate. Cultures $(40 \mathrm{ml})$ were harvested after $18 \mathrm{~h}$ of incubation with shaking at $37^{\circ} \mathrm{C}$, washed, and resuspended in $\mathrm{NaPO}_{4}$ buffer, $\mathrm{pH}$ 5.6. The cells were treated with lysosyme, $0.1 \mathrm{ml}$ of a $10 \mathrm{mg} / \mathrm{ml}$ solution, incubated on ice for $10 \mathrm{~min}$, and sonicated using a Branson sonifier at $40 \%$ power for 20 pulses. Cellular debris was removed by centrifugation; $16,000 \mathrm{rpm}$ for $30 \mathrm{~min}$ in a model SS34 rotor (DuPont-Sorvall). The supernatants were concentrated and tested for neuraminidase activity.

The isoelectric point of the cloned neuraminidase present in the $E$. coli sonicates was determined by applying aliquots of the cell extracts to an acrylamide-ampholyte isoelectric focusing (IEF) gel (PharmaciaLKB, Piscataway, NJ), pH 3.5-9, and focusing for $90 \mathrm{~min}$. Neuraminidase activity was identified using a MuNeuNAc overlay and visualization with an ultraviolet (UV) light source.

\section{Cloning procedures}

Cloning of nanA in E. coli LE392. The gene encoding the PAO1 neuraminidase, nanA, was isolated from a genomic library of PAO1 H103 cloned on the cosmid vector pLAFR and expressed in E. coli LE392. The initial screening for clones expressing neuraminidase activity was done by plating clones on M9 media containing MUNeuNAc and examining under a UV light source for fluorescence. Individual clones were then inoculated into a 96-well microtiter plate containing LuriaBertani media with tetracycline $(30 \mu \mathrm{g} / \mathrm{ml})$, incubated overnight at $37^{\circ} \mathrm{C}$, and lysed with lysosyme, $2 \mu \mathrm{l}$ of $10 \mathrm{mg} / \mathrm{ml}$ solution. MUNeuNAc was added to a final concentration of $25 \mu \mathrm{M}$ and fluorescence measured.

DNA manipulations were carried out using standard methods (33). Restriction endonucleases and T4 ligase were obtained commercially and used according to the suggestions of their manufacturers.

Determination of molecular weight. A partial purification of the PAO1 neuraminidase was done using a combination of chromatographic and IEF techniques. An aliquot of the concentrated PAO1 supernatant was applied to a DE52 anion exchange column (Whatman, Inc., Clifton, NJ). Neuraminidase activity was found in the unbound flow through material. The proteins remaining in the unbound fraction were separated by electrophoresis on an acrylamide IEF gel and neuraminidase activity was identified by using an overlay of 2.5 $\mathrm{mM}$ MuNeuNAc. The band of fluorescence was cut out of the IEF gel, and the protein was precipitated and applied to a $12 \%$ SDS polyacrylamide gel allowing the identification of the protein band associated with neuraminidase activity.

Partial purification of the $\mathrm{PAO1}$ neuraminidase. $\mathrm{PAO}$ was grown in $\mathrm{M} 9+10 \mu \mathrm{g} / \mathrm{ml} \mathrm{FeCl}_{2}$ to $\mathrm{OD}_{600} 0.6$ - and 800 -ml culture supernatants harvested by centrifugation at $8,000 \mathrm{rpm}$ for 15 minutes a $4^{\circ} \mathrm{C}$ in a model RC5C SS34 rotor (DuPont Sorvall). The supernatants were concentrated twenty times using polyethylene glycol, mol wt 20,000, then dialyzed exhaustively against $70 \mathrm{mM} \mathrm{NaPO}_{4}$, pH 5.75. This was applied to DE52 in a batch method. Unbound material was removed after $2 \mathrm{~h}$ at $4^{\circ} \mathrm{C}$ and applied to a CM52 column (Whatman, Inc.). Proteins were eluted using a stepwise gradient $0.105-0.245 \mathrm{M} \mathrm{NaPO}_{4}$ buffer. Fractions were tested for neuraminidase activity using the microtiter assay above. The appropriate fractions were pooled, concentrated and adjusted to $\mathrm{pH} 6.0$.

Analysis of neuraminidase activity and substrate profile. A modification of the thiobarbituric acid assay (37) was used to measure the release of sialic acid from a variety of substrates; $0.5 \%$ sialyllactose $(N$ acetylneuramin-lactose) in $35 \mathrm{mM} \mathrm{NaPO}_{4}$ buffer, pH 7.0, fetuin, 100 $\mathrm{mg} / \mathrm{ml}$ in $\mathrm{H}_{2} \mathrm{O}, 1 \%$ mucin from bovine submaxillary glands, $0.5 \% \mathrm{~N}$ - 
acetyllactosamine in $\mathrm{H}_{2} \mathrm{O}$. These assays were performed by adding 100 $\mu \mathrm{l}$ of substrate and $100 \mu \mathrm{l}$ of the partially purified PAO1 neuraminidase, or commercially obtained neuraminidase from $C$. perfringens as a control, and incubating for $24 \mathrm{~h}$ at $37^{\circ} \mathrm{C}$. The thiobarbituric assay was then performed (37). After cooling the reactions to room temperature, a 1-ml aliquot was extracted with $1 \mathrm{ml}$ of cyclohexanone. the layers were separated by centrifugation at $700 \mathrm{rpm}$ for $5 \mathrm{~min}$ in a model RC5C SS34 rotor. OD $_{549}$ of the upper cyclohexanone phase was read and millimolars of sialic acid were quantified by comparison to a standard curve obtained using dilutions of sialic acid $(\mathrm{N}$-acetylneuraminic acid) $0.1-1.0 \mathrm{mg}$.

Effect of neuraminidase on human epithelial cells. The release of sialic acid from human epithelial monolayers was measured by adding $5.16 \mu \mathrm{g}$ of the partially purified PAO1 enzyme $(6.0 \mathrm{ml})$ or $2.5 \mathrm{U}(2.27$ $\mathrm{mg}$ ) of the $C$. perfringens enzyme in the same $\mathrm{NaPO}_{4}$ buffer, or buffer alone as a control, to a T75 flask containing a confluent monolayer of primary respiratory epithelial cells obtained from normal human nasal polyps. The characteristics of these monolayers have been previously described in detail (17). After incubation for $18 \mathrm{~h}$ at $37^{\circ} \mathrm{C}$, the supernatants were harvested and cellular debris removed. The supernatants were lyophilized and resuspended in $0.2 \mathrm{ml}$ of $70 \mathrm{mM} \mathrm{NaPO}_{4}$ buffer, $\mathrm{pH}$ 5.75, and assayed for sialic acid content as above.

The effect of neuraminidase treatment of the epithelial monolayers on the adherence of PAO1 was determined using the adherence assay previously described (17). In brief, epithelial cells isolated from nasal polyps were grown to confluence in 24-well tissue culture plates. Triplicate wells were treated with either PBS, pH 6.5, $C$. perfringens neuraminidase $0.25 \mathrm{U}$ per well in $0.3 \mathrm{ml}$ of PBS, pH 6.5 , or the partially purified PAO1 neuraminidase $0.3 \mathrm{ml}$ per well, for $60 \mathrm{~min}$ at $37^{\circ} \mathrm{C}$. The plates were rinsed three times with PBS and incubated with ${ }^{35} \mathrm{~S}$-labeled PAO1 for $2 \mathrm{~h}$ at $37^{\circ} \mathrm{C}$. The epithelial cells and adherent bacteria were solubilized in $0.5 \mathrm{ml}$ of $2 \%$ sodium dodecyl sulfate and scintillations were counted (Tricarb liquid scintillation spectrophotometer, Packard Instrument Co., Inc., Downers Grove, IL). The scintillations associated with a $100-\mu \mathrm{l}$ aliquot of the initial $5 \times 10^{8} \mathrm{CFU} / \mathrm{ml}$ PAO1 suspension were counted to determine the CFU/cpm. A mean, standard deviation (SD), and standard error (SE) were determined. Statistical analysis was performed using StatView software (Abacus Concepts, Inc., Berkeley, CA).

\section{Results}

Identification and partial purification of the neuraminidase activity in PAO1 culture supernatants. The neuraminidase isolated from late log-phase M9 culture supernatants was found to have an approximate molecular mass of $51 \mathrm{kD}$ as estimated

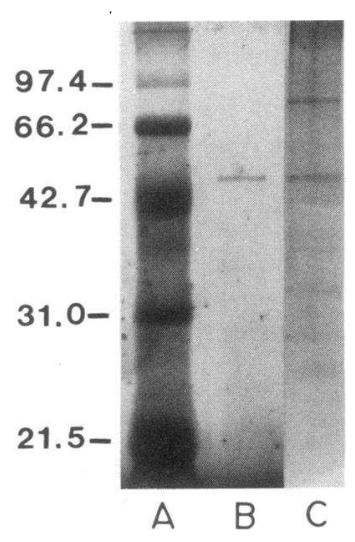

Figure 1. Isolation of the PAO1 neuraminidase from culture supernatants. (A) Molecular weight standards $(B)$ Protein associated with neuraminidase activity. The proteins not bound to DE52 were electrophoresed on a preparative IEF gel, pH gradient 3.59.0. The neuraminidase activity was identified using a MUNeuNAc overlay and the corresponding band cut from the IEF gel. The protein in this gel slice was precipitated with trichloroacetic acid, electrophoresed on $12 \%$ polyacrylamide gel, and visualized with silver staining. $(C)$ Partially purified neuraminidase preparation. A semiquantitative isolation of the neuraminidase was performed by applying the supernatant proteins not bound to DE52 to a CM52 column. The fractions eluted with $0.1 \mathrm{M} \mathrm{NaPO}_{4}$ were associated with the neuraminidase activity and contained the proteins visualized here with silver staining.
Table I. Partial Purification of PAO1 Neuraminidase

\begin{tabular}{lcccrr}
\hline & $\begin{array}{c}\text { Protein } \\
\text { concentration }\end{array}$ & $\Delta F^{*}$ & $\Delta F / \mathrm{ml}$ & \multicolumn{1}{|c}{$\begin{array}{c}\Delta F / \mathrm{mg} \\
\text { protein }\end{array}$} & $\begin{array}{c}\text { Fold } \\
\text { purification }\end{array}$ \\
\hline & $\mu m / m l$ & \multicolumn{2}{c}{$n m$} \\
Supernatant & 103.00 & 376 & 1,880 & 18,252 & \\
DE52 unbound & 22.50 & 256 & 1,280 & 56,889 & $3 \times$ \\
CM52 eluent & 0.86 & 289 & 1,445 & $1,680,232$ & $92 \times$ \\
& & & & & \\
\hline
\end{tabular}

* As determined by MUNeuNAc microtiter plate assay in $200 \mu \mathrm{l}$ per well.

from its electrophoretic mobility on SDS-polyacrylamide gels (Fig. 1) and was isoelectric at pH 8.14.

More quantitative yields of the enzyme were isolated using a combination of anion and cation exchange column chromatography (Table I). In addition to the $51 \times 10^{3} M_{\mathrm{r}}$ protein corresponding to the neuraminidase activity identified using an overlay of the fluorescent substrate MUNeuNAc, a second protein with an $86 \times 10^{3} M_{\mathrm{r}}$ copurified with the neuraminidase (Fig. 1). Separation of the high molecular weight protein by HPLC was performed and there was no neuraminidase activity associated with this protein (data not shown).

The activity of preparations containing the partially purified neuraminidase, visualized in Fig. 1, in releasing sialic acid from a number of substrates was determined (Table II). The specific activity of the partially purified enzyme was two orders of magnitude greater than that of the $C$. perfringens enzyme against substrates expected to contain sialic acid primarily in an $\alpha 2,3$ configuration such as sialyllactose. The Pseudomonas enzyme had even greater specific activity (three orders of magnitude) in releasing sialic acid residues from human epithelial cells, which contain membrane gangliosides usually sialylated in an $\alpha 2,6$ configuration.

Inhibitors of the partially purified PAO1 neuraminidase included 2,3 dehydro-2-deoxy- $N$-acetylneuraminic acid, sialic acid, $\mathrm{CaCl}_{2}$, and EDTA (Table III). When incubated for $48 \mathrm{~h}$ activity was inhibited by each of these compounds by $>90 \%$. Using the hydrolysis of MUNeuNAc to detect neuraminidase activity, the PAOl enzyme continued to be active at $37^{\circ} \mathrm{C}$ for up to $72 \mathrm{~h}$.

Modification of epithelial cells by the PAOI neuraminidase. The effect of the PAO1 neuraminidase on primary cultures of human respiratory epithelial cells was tested by measuring the adherence of ${ }^{35}$ S-labeled PAO1 to confluent monolayers under control conditions and after exposure to PAO1 neuraminidase. If asialogangliosides function as receptors in this model system, we would expect that neuraminidase-treated monolayers should bind increased numbers of Pseudomonas. As shown in Fig. 2, PAO1 adherence to epithelial cells was increased by $37.5 \%$ after the monolayers were incubated with partially purified PAO1 neuraminidase $(P<0.0019)$, and $18.6 \%$ after treatment with $C$. perfringens neuraminidase as compared to the PBS-treated control $(P<0.02)$. These effects were seen with very small amounts of neuraminidase; one-tenth the amount of $C$. perfringens enzyme used to quantitate the sialic acid released (Table II), as was used in the adherence assays; for the PAO1 enzyme the increase in adherence was associated with $\sim$ 1/100 of the Warren assays. Larger amounts of the PAO1 neuraminidase disrupted the integrity of the monolayer and caused peeling from the collagen-coated plastic. Although this 
Table II. Release of Sialic Acid (NANA) by Neuraminidase

\begin{tabular}{lcc}
\hline \multirow{2}{*}{ Substrate } & \multicolumn{2}{c}{ Neuraminidase } \\
\cline { 2 - 3 } & C. perfringens & P. aeruginosa PAO1 \\
\hline N-Acetylneuraminlactose & $14.6^{*}$ & $1255.8^{\ddagger}$ \\
Fetuin & $14.8^{*}$ & $3814.0^{\ddagger}$ \\
Bovine mucin & $15.8^{*}$ & $4162.8^{\ddagger}$ \\
Normal human nasal polyp & $0.028^{\S}$ & $24.0^{\| 1}$ \\
$N$-Acetyllactosamine & $\mathrm{ND}^{* 1}$ & $\mathrm{ND}^{\ddagger}$ \\
\hline
\end{tabular}

* $45 \mu \mathrm{g}=0.05 \mathrm{U}$ used. ${ }^{\ddagger} 86 \mathrm{ng}$ used. $\$ 2.27 \mathrm{mg}=2.5 \mathrm{U}$ used. " 5.16 $\mu \mathrm{g}$ used. 'ND, none detected.

did not interfere with the Warren assay, it did limit the amount of enzyme which could be used in the adherence assays.

Regulation of neuraminidase expression in PAO1. Central regulatory genes are often involved in the coordinate expression of the virulence factors (38). Specific environmental conditions can activate the expression of these regulatory systems. To determine if any of the previously characterized Pseudomonas regulatory genes might also control nanA, neuraminidase expression was quantified in isogenic pairs of strains containing mutations in specific regulatory genes. The strains were grown under conditions expected to maximize expression of the virulence determinant to be tested. The genetic elements screened included: $\operatorname{tox} R(\operatorname{reg} A)$ associated with $\mathrm{Fe}^{++}$-dependent exotoxin A expression $(29,34), r p o N$, involved in pilus and flagellar expression and nitrogen metabolism (28), and $\operatorname{alg} R$, involved in the osmoregulation of alginate production (39).

Neuraminidase activity in supernatants produced by PA103, and the ToxR ${ }^{-}$PA103-29 under conditions of limited $\mathrm{Fe}^{++}$was equivalent (Fig. $3 A$ ). In the presence of $10 \mu \mathrm{g} / \mathrm{ml} \mathrm{Fe}^{++}$ neuraminidase production was increased in both of these strains during stationary phase of growth, a pattern of regulation which is not typical for ToxR-regulated genes (40). Neuraminidase production was not dependent upon the expression of $r p o N$ as both PAK and PAK N1 produced neuraminidase in amounts dependent upon the availability of nitrogen and overall growth rate (Fig. $3 \mathrm{~B}$ ).

As increased osmolarity has been an important environmental factor in the expression of the CF specific Pseudomonas virulence factor alginate, the effect of high salt was tested on the expression of the PAO1 neuraminidase (Fig. 4). There was a $50 \%$ increase in neuraminidase activity in supernatants from PAO1 grown in $\mathrm{M} 9+400 \mathrm{mM} \mathrm{NaCl}(1,038$ mosmol $)$ as compared to control cultures grown in M9 $(238$ mosmol) $(P$ $<0.0004)$. This effect could be completely negated by the addition of the osmoprotectant glycine betaine. Control assays to determine the effect of $400 \mathrm{mM}$ salt on the activity of the enzyme were performed. PAO1 supernatant was associated with a $\Delta F-280$; in the presence of $400 \mathrm{mM} \mathrm{NaCl}, \Delta F-185$, a $34 \%$ decrease. Thus, $\mathrm{NaCl}$ by itself was not responsible for the enhanced hydrolysis of MUNeuNAc. The increase in neuraminidase activity in response to high salt was not limited to strain PAO1. Strain PAK demonstrated a similar increase. PAK N1 with a fourfold increase had an exaggerated response to hyperosmolar growth conditions.

AlgR 1 and AlgR2 are required for the osmoregulation of neuraminidase expression. High osmolarity is one of the sig-
Table III. Inhibitors of PAOI Neuraminidase Activity

\begin{tabular}{lcc}
\hline & $\Delta F$ & Percent decrease \\
\hline & $n m$ & \\
PAO1 partially purified neuraminidase & 510 & - \\
+1 mM 2,3 dehydro-2-deoxy-NANA* & 251 & 51 \\
+10 mM 2,3 dehydro-2-deoxy-NANA & 187 & 63 \\
+10 mM NANA & 213 & 58 \\
+25 mM NANA & 145 & 72 \\
+50 mM NANA & 96 & 81 \\
+10 mM sucrose & 426 & 16 \\
+50 mM sucrose & 430 & 16 \\
+1 mM CaCl & 353 & 23 \\
+10 mM CaCl & 268 & 42 \\
+0.025 mM EDTA & 220 & 52 \\
+0.050 mM EDTA & 218 & 53 \\
\hline
\end{tabular}

* NANA, $N$-Acetylneuraminic acid.

nals involved in the transcriptional activation of $\operatorname{alg} D$ which encodes GDP mannose dehydrogenase, the enzyme critical for the production of alginate characteristic of the mucoid phenotype of Pseudomonas present in CF $(9,41,42)$. The expression of algD can be regulated by AlgR 1 (AlgR), a member of the two component family of response regulators $(39,43)$ and by AlgR2 (AlgQ) (41, 44).

To determine if mutations in algR1 or algR2 might affect the osmo-dependent regulation of nan $A$, the specific neuraminidase activity in $P$. aeruginosa strains 8830 (constitutive mucoid), 8852 (algR1) and 8882 (algR2) were compared after growth under normal and conditions of increased osmolarity (Fig. 5). The expression of neuraminidase by 8830 was increased by $50 \%$ in the presence on $400 \mathrm{mM} \mathrm{NaCl}(P<0.006)$. Both algR mutants had decreased neuraminidase production

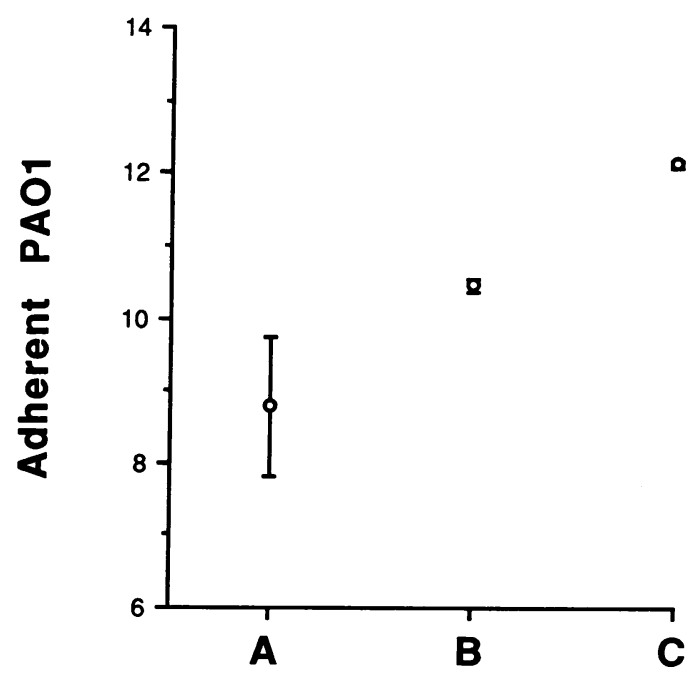

Figure 2. The effect of neuraminidase on PAO1 adherence to respiratory epithelial cells. The number of ${ }^{35} \mathrm{~S}$-labeled PAO1 adherent to confluent epithelial monolayers is plotted on the $y$-axis. The monolayers were preincubated with for $60 \mathrm{~min}$ at $37^{\circ} \mathrm{C}$ with $(A)$ control PBS pH 6.5, $(B) C$. perfringens neuraminidase $0.25 \mathrm{U}$ per well in PBS, pH 6.5, $(C)$ partially purified PAO1 neuraminidase in PBS, pH 6.5. The data are expressed as the mean $\pm \operatorname{SE}(n+3) \times 10^{6} \mathrm{CFU} / \mathrm{ml}$. The $\mathrm{SE}$ of some data points is contained within the symbol of the mean. 

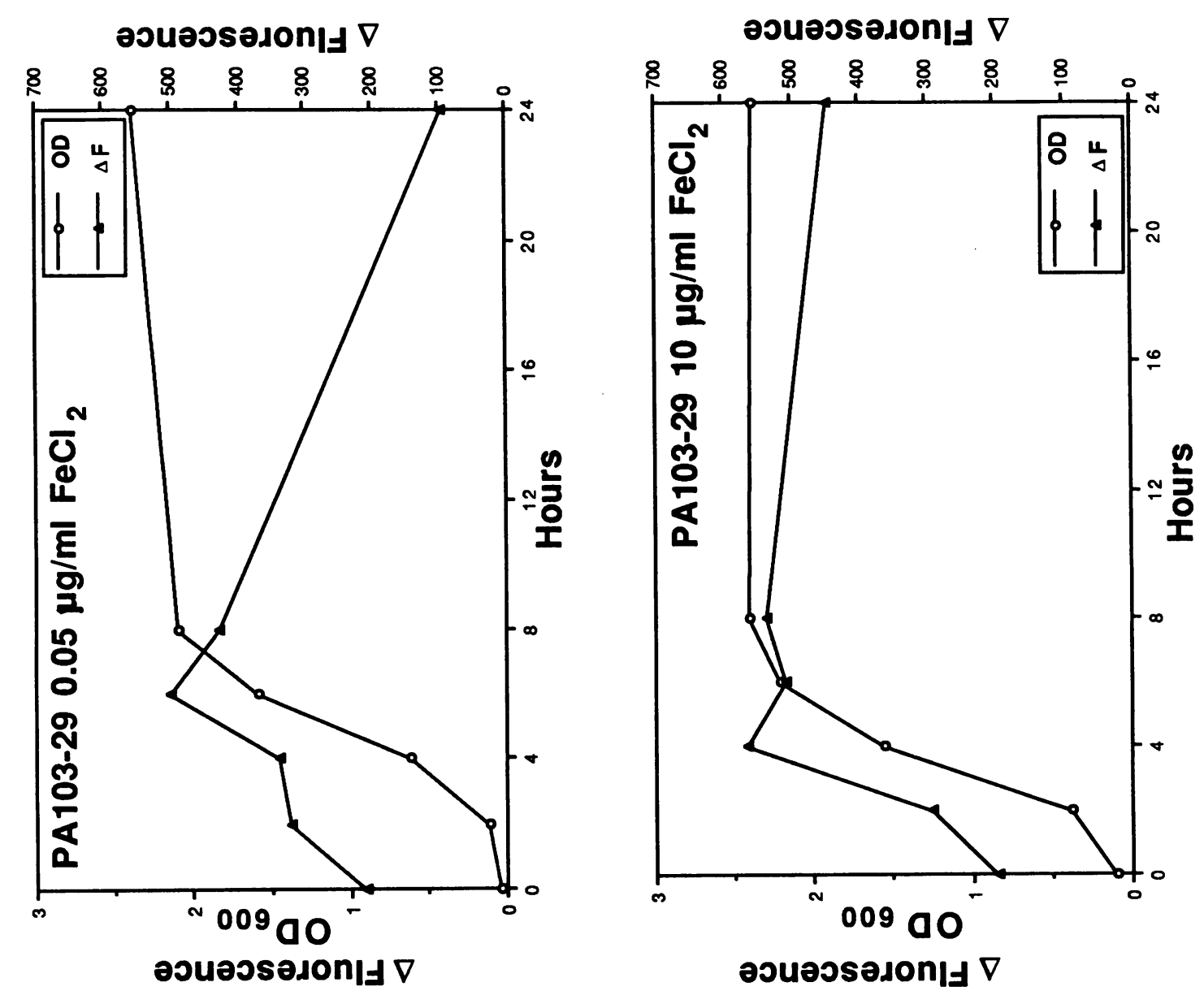

究

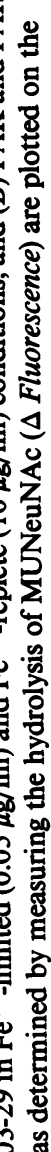

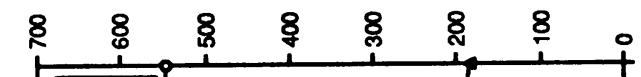

起
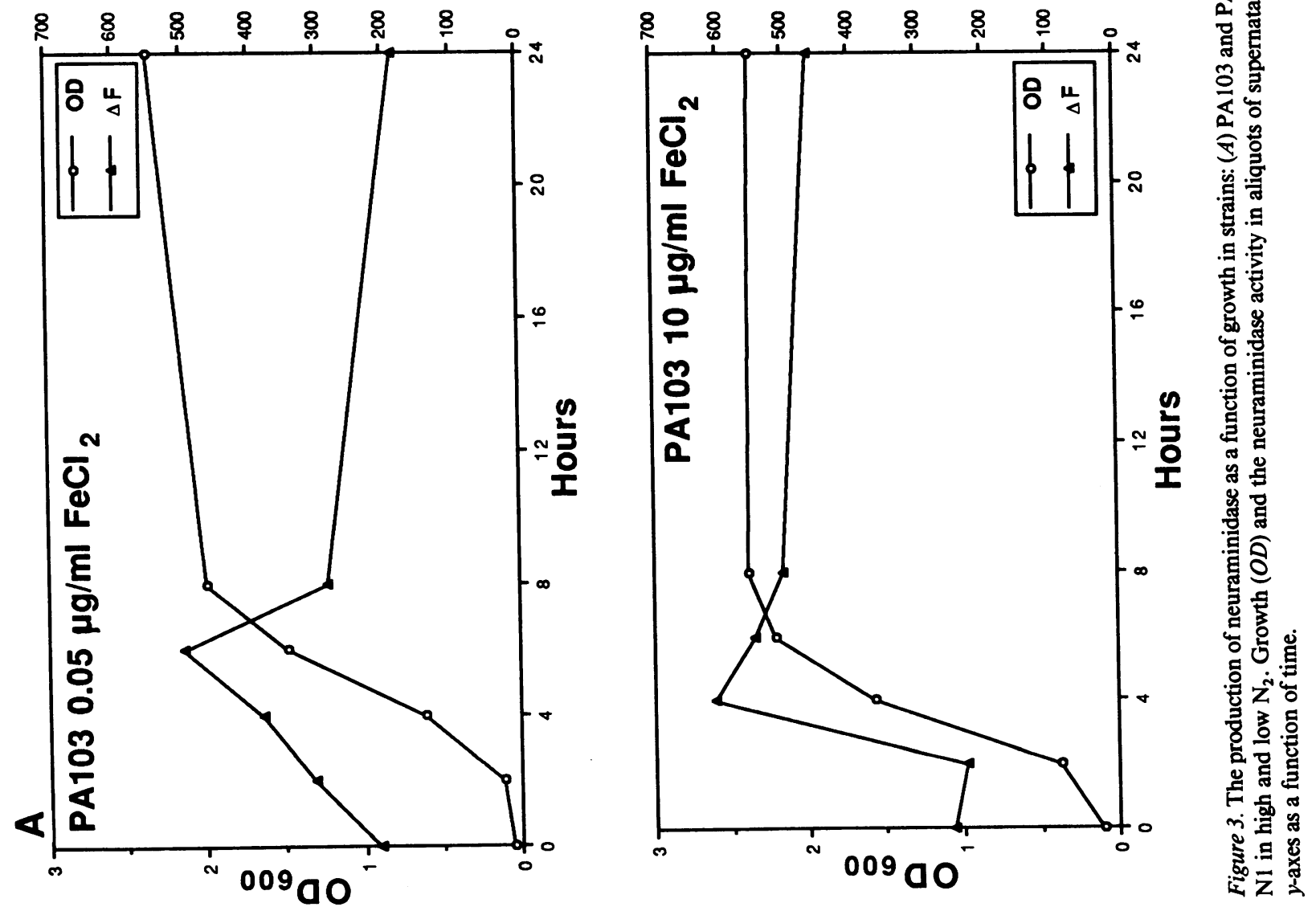

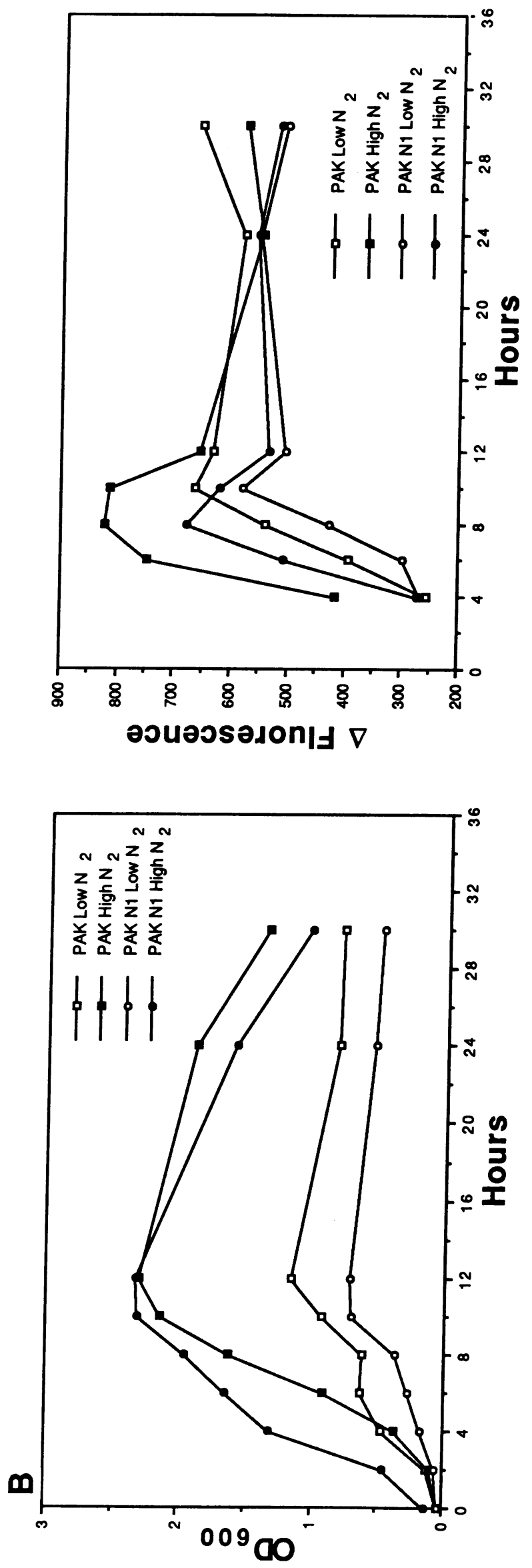

under control conditions. The algR 1 mutant had a diminished response to high salt. The algR 2 mutant had an actual decrease in neuraminidase production under hyperosmolar conditions. Thus, similar osmoregulatory systems may be involved in the expression of both alginate and neuraminidase.

Osmoregulation of nanA expressed in $E$. coli. To further analyze the regulation of neuraminidase expression, the structural gene for the PAO1 enzyme, nanA was cloned and neuraminidase production quantified in an $E$. coli background. The nanA cosmid, pASP101, contained a 7.5-kb EcoR1 fragment associated with the production of a neuraminidase with the same isoelectric point as that present in sonicates of PAO1 (Fig. 6). The 7.5-kb DNA fragment was verified by Southern hybridization to have originated from PAO1 (data not shown).

The expression of neuraminidase by $E$. coli MC4100pASP101 was osmoregulated (Fig. 7). There was a 2.6-fold increase in activity in response to $400 \mathrm{mM} \mathrm{NaCl}$ (1,697 mosmol) $(P<0.004)$, a 2.4 -fold increase in response to $400 \mathrm{mM} \mathrm{KCl}$ (1697 mosmol), and a 2.2-fold increase in response to $20 \%$ sucrose (881 mosmol). In the presence of an osmoprotectant, $2.5 \mathrm{mM}$ glycine betaine, the effect of high salt was completely abolished.

The osmotic regulation of nanA in $E$. coli was dependent upon OmpR (Fig. 8). In the OmpR ${ }^{-}$mutant MH225.101 nanA expression was equivalent in cultures grown under control conditions or in $400 \mathrm{mM} \mathrm{NaCl}$. When the $o m p R$ mutation was complemented by genes expressed on the plasmid pFR29, osmodependent nanA expression was restored. This is analogous to the transcriptional activation of $\operatorname{alg} D$ by $O \mathrm{mpR}$ when measured in an $E$. coli background. OmpR can activate algD under conditions of high osmolarity functionally replacing AlgR 1 (39).

\section{Discussion}

Although the production of neuraminidase by Pseudomonas was originally reported over 30 years ago (25) the function of

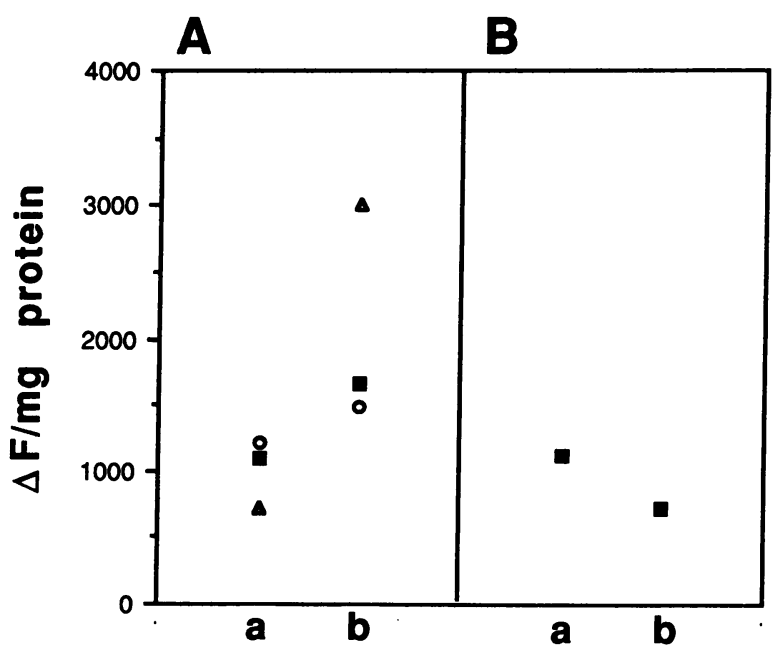

Figure 4. The effect of high osmolarity on the production of neuraminidase. $(A)$ The neuraminidase specific activity of late log culture supernatants of strains PAOI (๘), PAK (O), and PAK N1 $(\Delta)$ are shown. Cultures were grown in (a) M9 (238 mosmol), (b) M9 + 400 $\mathrm{mM} \mathrm{NaCl}$ (1038 mosmol) $(B)$ The effect of an osmoprotectant. PAOl cultures were grown in (a) $\mathrm{M} 9$ media $+1 \mathrm{mM}$ glycine betaine and (b) $\mathrm{M} 9+400 \mathrm{mM} \mathrm{NaCl}+1 \mathrm{mM}$ glycine betaine. 


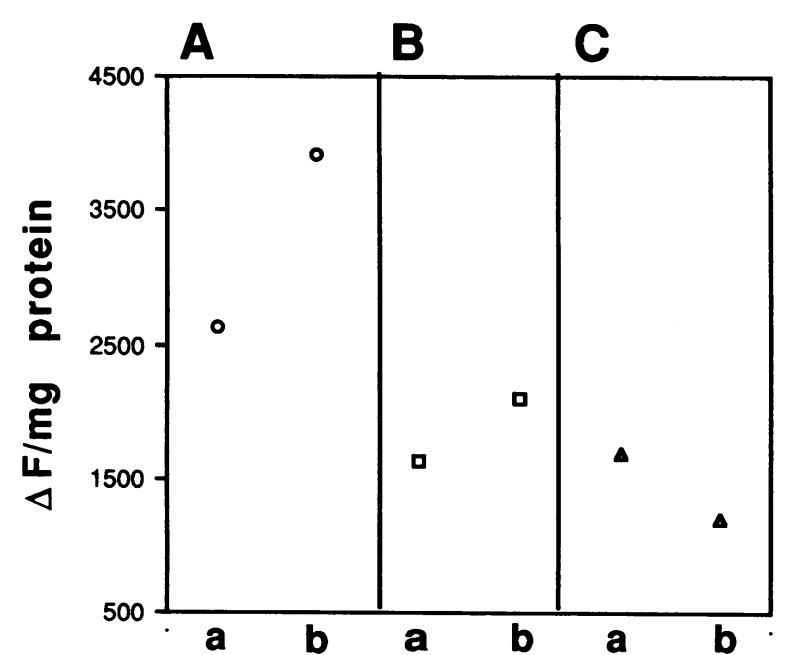

Figure 5. The effect of mutations in $\operatorname{algR} 1$ and $\operatorname{alg} R 2$ on the production of neuraminidase. The neuraminidase specific activity in supernatants harvested from late log-phase cultures grown in $(a)$ M9 media and $(b) \mathrm{M} 9+400 \mathrm{mM} \mathrm{NaCl}$ was determined for $P$. aeruginosa strains: (A) 8830 (O), (B) 8852 () (algRI), (C) 8882 ( $\triangle$ ) (algR2).

this enzyme in the physiology of $P$. aeruginosa or its role in the pathogenesis of infection remains to be established. In the respiratory tract there are several potential substrates for the action of neuraminidase. The glycoproteins which comprise respiratory mucins are highly sialylated and epithelial membranes have abundant sialylated ganglioside and other glycoconjugate components (45). The PAO1 neuraminidase was active against a range of substrates expected to be present in the respiratory tract, including $\alpha 2,3$-linked sialic acids as found in sialyllactose as well as the sialic acid residues present on epithelial cell surfaces.

The properties of the PAO1 neuraminidase were quite similar to those of other bacterial neuraminidases in general (19), as well as to the $P$. aeruginosa neuraminidase originally characterized by Leprat and Michel-Briand (26). Although the purification procedure used did not allow a definitive estimation of the $M_{\mathrm{r}}$, the data obtained is consistent with previously described neuraminidases. The 86,000 -D protein found in all supernatant fractions with neuraminidase activity is close in size to the $V$. cholerae neuraminidase, $M_{\mathrm{r}} 90,000$ (31), and that of $C$. perfringens, $M_{\mathrm{r}} 88,000$ (46). The active enzyme identified on a nondenaturing ampholyte-acrylamide IEF gel was associated with a reduced and denatured protein band with $M_{\mathrm{r}} 51,000$ which is closer in size to some of the viral neuraminidases (19). However, this may represent a product or subunit structure of the $86-\mathrm{kD}$ protein. Subcloning and DNA sequencing studies will clarify this question in the future. The substrate profile, stability, and inhibition by $\mathrm{CaCl}_{2}, 2,3$-dehydro-2-deoxy $\mathrm{N}$-acetylneuraminic acid and by $N$-acetylneuraminic acid were quite similar to the reported properties of the $V$. cholerae enzyme (47), with which it shares an isoelectric point, and DNA homology (A. Prince, unpublished data).

The activity of the PAO1 neuraminidase differed from the C. perfringens enzyme most significantly, by its 1,000-fold greater activity in releasing sialic acid from the epithelial monolayers. As previous studies suggested that much of the superficial sialic acid available for lectin binding on these epithelial monolayers is present in an $\alpha 2,6$ configuration (Saiman, L., et al., manuscript submitted), this may represent an increased activity particularly against the multiply sialylated gangliosides typical of membrane glycolipids $(48,49)$.

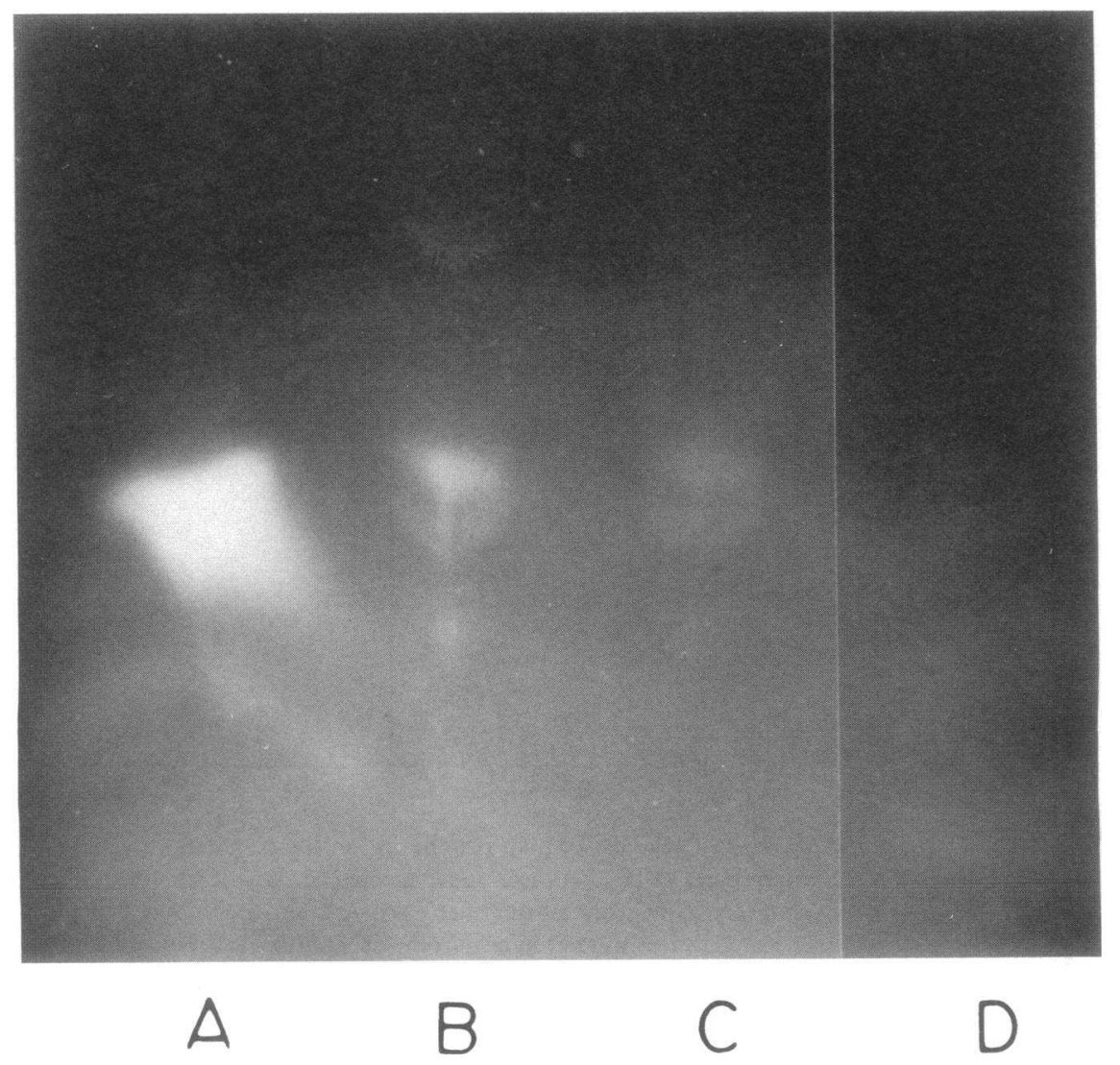

Figure 6. Expression of the cloned PAO1 neuraminidase in $E$. coli as detected by a MUNeuNAc overlay of an IEF gel. Cell sonicates from $(A)$ LE392pCVD364, $(B)$ PAO1, (C) LE392pASP101, and (D) LE392pLAFR. 
Asialogangliosides that contain a GalNAc $\beta 1-4 \mathrm{Gal}$ sequence have been shown to act as receptors for at least two discrete Pseudomonas adhesins, pilin (50), and exoenzyme S (51). Their common GalNAc $\beta 1-4 \mathrm{Gal}$ receptor is a constituent of many gangliosides, but is not a sequence typical for mucin glycoproteins. Inasmuch as recent studies have failed to demonstrate specific receptor sequences for $P$. aeruginosa in human mucin glycoproteins (52), these asialoganglioside receptors appear to be of major importance in mediating Pseudomonas attachment to the respiratory tract. The activity of the neuraminidase in modifying membrane glycolipids and exposing these potential receptors is consistent with the observation that neuraminidase treatment of the epithelial monolayers increased bacterial attachment, and correlated with the release of sialic acid from the monolayers.

Many respiratory pathogens recognize these or similar GalNAc $\beta 1-4 \mathrm{Gal}$ carbohydrate binding sites in vitro (18), yet do not selectively colonize CF patients in vivo. Thus, these receptors must not be equally accessible to all potential pathogens. Because Pseudomonas does not colonize the normal respiratory tree, but is peculiar to patients with cystic fibrosis, environmental factors specific to cystic fibrosis such as increased osmolarity may be important in triggering the expression of specific genes that facilitate colonization. Although the osmolarity of the uninfected CF lung has not been directly measured, current understanding of the consequences of the abnormal CF transmembrane conductance regulator suggests that this milieu is hyperosmolar $(11,52)$. Under these conditions, nan $A$ is likely to be expressed.

It seems improbable that the modest biological effect of neuraminidase on the epithelial cell surface could account for the virtually universal colonization of CF patients with $P$. aeruginosa. However, the milieu of the $\mathrm{CF}$, but not the normal lung, may specifically activate the expression of several genes, including nan $A$, which initiate colonization and facilitate longterm infection. The potentiation of neuraminidase activity by proteases may further facilitate this process (45).

The osmoregulation of nanA expression appears to share several features with the genes associated with the expression of the mucoid phenotype pathognomonic for chronic Pseudomonas infection in CF. The control of alginate biosynthesis is

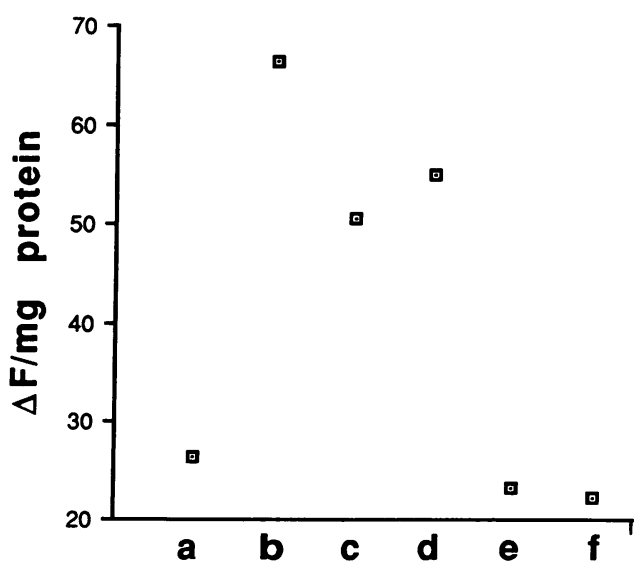

Figure 7. The expression of nanA in E. coli MC4100. The neuraminidase specific activity in sonicates of MC4100pASP101 grown under the following conditions is plotted: (a) M9; (b) M9 + $400 \mathrm{mM} \mathrm{NaCl}$; (c) $\mathrm{M} 9+20 \%$ sucrose; (d) $\mathrm{M} 9+400 \mathrm{mM} \mathrm{KCl} ;(e) \mathrm{M} 9+2.5 \mathrm{mM}$ glycine betaine; and $(f) \mathrm{M} 9+400 \mathrm{mM} \mathrm{NaCl}+2.5 \mathrm{mM}$ glycine betaine.

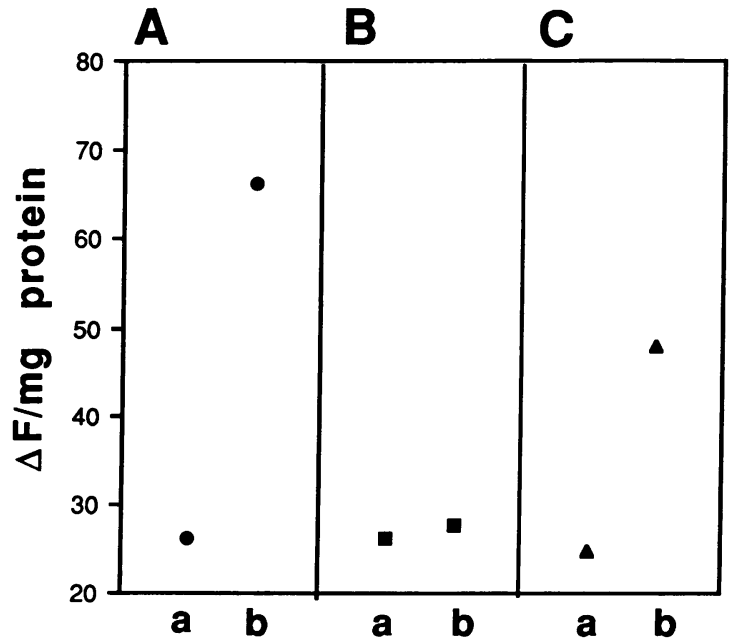

Figure 8. The effect of OmpR on nanA expression. The neuraminidase specific activity in sonicates of cultures of $(A)$ MC4100pASP101, (B) MH225.101pASP101, and (C) MH225.101pASP101/pFR29 grown in $(a) \mathrm{M} 9$ and $(b) \mathrm{M} 9+400 \mathrm{mM} \mathrm{NaCl}$ are shown.

highly complex involving several separate regulatory elements, some of which respond to increased osmolarity. Pseudomonas analogue of the $o m p R$-enz $V$ system (39), ntrC-type regulators (53), and rpoN dependent genes (42) have been implicated. The studies presented exclude a major role for $r p o N$-dependent genes in the expression of nanA. Nor was the regulatory gene tox $R$ implicated, despite its central role in the regulation of the classic Pseudomonas virulence factors (40). However, the osmodependent expression of neuraminidase required both $a \lg R 1$ and $\operatorname{alg} R 2$, which are similarly involved in the osmodependent expression of algD, the critical enzyme in alginate synthesis $(41,43)$. The osmoregulation of nanA by the $E$. coli response regulator OmpR, suggests that neuraminidase also belongs to the "two-component" family of environmentally regulated proteins (38). This demonstration that "cross-talk" is responsible for the activation of nanA by $O \mathrm{mpR}$, is further evidence that transcription of this gene is similarly regulated by an analogous two-component system of signal transduction. Thus, key elements of the genetic regulation of alginate and neuraminidase expression are shared.

These studies suggest that specific environmental conditions and corresponding regulatory genes may be involved in both the initial selection of strains, which can modify the epithelial surface and adhere and the eventual selection of the alginate-producing strains, which elude the normal host defense mechanisms to establish a chronic infection. Interruption of the activation of these genes in vivo might be accomplished by elimination of the environmental signal, high osmolarity. Therapeutic strategies to increase hydration within the CF lung (54) may be a practical strategy to prevent the expression of the Pseudomonas genes that allow colonization of the respiratory tract to occur.

\section{Acknowledgments}

We thank Nicholas Cacalano for assistance in the purification of the neuraminidase.

This work was supported by The Cystic Fibrosis Foundation and by U. S. Public Health Service grant DK-39693 to Dr. Prince. Dr. Kays was the recipient of a postdoctoral research fellowship from the Cystic Fibrosis Foundation-Research Development Program at Columbia University. 


\section{References}

1. Liu, P. V. 1974. Extracellular toxins of Pseudomonas aeruginosa. J. Infect. Dis. 130(Suppl.):94-99.

2. Horvat, R. T., and M. J. Parmely. 1988. Pseudomonas aeruginosa alkaline protease degrades human gamma interferon and inhibits its bioactivity. Infect. Immun. 56:2925-2932.

3. Bejarano, P. A., J. P. M. Langeveld, B. G. Hudson, and M. E. Noelken. 1989. Degradation of basement membranes by Pseudomonas aeruginosa elastase. Infect. Immun. 57:3783-3787.

4. Klinger, J. D., B. Tandler, C. M. Liedtke, and T. F. Boat. 1984. Proteinases of Pseudomonas aeruginosa evoke mucin release by tracheal epithelium. J. Clin. Invest. 74:1669-1678.

5. Iglewski, B. H., and D. Kabat. 1975. NAD-dependent inhibition of protein synthesis by Pseudomonas aeruginosa toxin. Proc. Natl. Acad. Sci USA. 72:22842288.

6. Coburn, J., S. T. Dillon, B. H. Iglewski, and D. M. Gill. 1989. Exoenzyme S of Pseudomonas aeruginosa ADP-ribosylates the intermediate filament protein vimentin. Infect. Immun. 57:996-998.

7. Ostroff, R. M., B. Wretlind, and M. L. Vasil. 1989. Mutations in the hemolytic-phospholipase $\mathrm{C}$ operon result in decreased virulence of Pseudomonas aeruginosa PAO1 grown under phosphate limiting conditions. Infect. Immun. 57:1369-1373.

8. Hoiby, N. 1974 Pseudomonas aeruginosa infection in cystic fibrosis: relationship between mucoid strains of Pseudomonas aeruginosa and the humoral immune response. Acta Pathol. Microbiol. Scand. Sect. B. 82:551-558.

9. Berry, A., J. D. DeVault, and A. M. Chakrabarty. 1989. High osmolarity is a signal for enhanced algD transcription in mucoid and nonmucoid Pseudomonas aeruginosa strains. J. Bacteriol. 171:2312-2317.

10. DeVault, J. D., K. Kimbara, and A. M. Chakrabarty. 1990. Pulmonary dehydration and infection in cystic fibrosis: evidence that ethanol activates gene expression and induction of mucoidy in Pseudomonas aeruginosa. Mol. Microbiol. 4:737-745.

11. Boucher, R. C., E. H. C. Cheng A. M. Paradiso, M. J. Stutts, M. R. Knowles, and H. S. Earp. 1989. Chloride secretory response of cystic fibrosis human airway epithelia. J. Clin. Invest. 84:1424-1431.

12. Li, M., J. D. McCann, C. M. Liedtke, A. C. Nairn, P. Greengard, and M. J. Welsh 1988. Cyclic AMP-dependent protein kinase opens chloride channels in normal but not cystic fibrosis airway epithelium. Nature (Lond.). 331:358-360.

13. Hollsing, A. E., M. Granstrom, M. L. Vasil, B. Wretlind, and B. Strankvik. 1987. Prospective study of serum antibodies to Pseudomonas aeruginosa exoproteins in cystic fibrosis. J. Clin. Microbiol. 25:1868-1874.

14. Ramphal, R., and M. Pyle. 1983. Adherence of mucoid and nonmucoid Pseudomonas aeruginosa to acid-injured tracheal epithelium. Infect. Immun. 41:345-351.

15. Woods, D. E., J. A. Bass, W. G. Johanson, Jr., and D. C. Straus. 1980 Role of adherence in the pathogenesis of Pseudomonas aeruginosa lung infection in cystic fibrosis patients. Infect. Immun. 30:694-699.

16. Ramphal, R., P. A. Small, J. W. Shands, Jr., W. Fischlschweiger, and P. A Small, Jr. 1980. Adherence of Pseudomonas aeruginosa to tracheal cells injured by influenza virus or by endotracheal intubation. Infect. Immun. 27:614-619.

17. Saiman, L., K. Ishimoto, S. Lory, and A. S. Prince. 1990. The effect of piliation and exoproduct expression on the adherence of Pseudomonas aeruginosa to respiratory epithelial monolayers. J. Infect. Dis. 161:541-548.

18. Krivan, H. C., D. D. Roberts, and V. Ginsburg. 1988. Many pulmonary pathogenic bacteria bind specifically to the carbohydrate sequence GalNAc $\beta 1$ 4Gal found in some glycolipids. Proc. Natl. Acad. Sci USA. 85:6157-6161.

19. Drzeniek, R. 1972. Viral and bacterial neuraminidases. Curr. Top. Microbiol. Immunol. 59:35-74.

20. Moncla, B. J., P. Braham, and S. L. Hillier. 1990. Sialidase (neuraminidase) activity among gram-negative anaerobic and capnophilic bacteria. J. Clin Microbiol. 28:422-425.

21. Brown, J. G., and D. C. Straus. 1987. Characterization of neuraminidases produced by various serotypes of group B streptococci. Infect. Immun. 55:1-6.

22. Camara, M., T. J. Mitchell, P. W. Andrew, and G. J. Boulnois. 1991 Streptococcus pneumoniae produces at least two distinct enzymes with neuraminidase activity: cloning and expression of a second neuraminidase gene in Escherichia coli. Infect. Immun. 59:2856-2858.

23. Berry, A. M., J. C. Paton, E. M. Glare, D. Hansman, and D. E. A. Catche-

side. 1988. Cloning and expression of the pneumococcal neuraminidase gene in Escherichia coli. Gene. 71:299-305.

24. Kabir, S., N. Ahmad, and S. Ali. 1984. Neuraminidase production by Vibrio cholerae 01 and other diarrheagenic bacteria. Infect. Immun. 44:747-749.

25. Shilo, M. 1957. The breakdown of the lactose derivative by bacteria. Biochem. J. 66:48-49.

26. Leprat, R., and Y. Michel-Briand. 1980. Extracellular neuraminidase production by a strain of Pseudomonas aeruginosa isolated from cystic fibrosis. Ann. Microbiol. (Inst. Past.). 131:210-220.

27. Vimr, E. R and F. A. Troy, 1985. Identification of an inducible catabolic system for sialic acids (nan) in Escherichia coli. J. Bacteriol. 164:845-853.

28. Totten, P. A., J. C. Lara, and S. Lory. 1990. The rpoN gene product of
Pseudomonas aeruginosa is required for expression of diverse genes including the flagellin gene. J. Bacteriol. 172:389-396.

29. Ohman, D. E., J. C. Sadoff, and B. H. Iglewski. 1980. Toxin-A deficient mutants of Pseudomonas aeruginosa PA 103: isolation and characterization. In fect. Immun. 28:899-908.

30. Darzins, A., and A. M. Chakrabarty. 1984. Cloning of genes controlling alginate biosynthesis from a mucoid cystic fibrosis isolate of Pseudomonas aeruginosa. J. Bacteriol. 159:9-18.

31. Vimr, E. R., L. Lawrisuk, J. Galen, and J. B. Kaper. 1988. Cloning and expression of the Vibrio cholerae neuraminidase gene nan $\mathrm{H}$ in Escherichia coli. J. Bacteriol. 170:1495-1504.

32. Hall, M. N., and Silhavy. 1981. Genetic analysis of the ompB locus in Escherichia coli K-12. J. Mol. Biol. 146:23-43.

33. Maniatis, T., E. F. Frisch, and J. Sambrook. 1989. Molecular Cloning: A Laboratory Manual. Cold Spring Harbor Laboratory, Cold Spring Harbor, NY.

34. Bjorn, M. J., B. H. Iglewski, S. K. Ives, J. C. Sadoff, and M. L. Vasil. 1978. Effect of iron on yields of exotoxin A in cultures of Pseudomonas aeruginosa PA-103. Infect. Immun. 19:785-791.

35. Myers, R. W., R. T. Lee, Y. C. Lee, G. H. Thomas, L. W. Reynolds, and Y Uchida. 1980. The synthesis of 4-methylumbelliferyl $\alpha$-ketoside of $N$-acetylneuraminic acid and its use in a fluorometric assay for neuraminidase. Anal. Biochem. 101:166-174.

36. Bradford, M. M. 1976. A rapid and sensitive method for the quantification of microgram quantities of protein utilizing the principle of protein-dye binding. Anal. Biochem. 72:248-254.

37. Warren, L. 1959. The thiobarbituric acid assay of sialic acids. J. Biol. Chem. 234:1971-1975.

38. Miller, J. F., J. J. Mekalanos, and S. Falkow. 1989. Coordinate regulation and sensory transduction in the control of bacterial virulence. Science (Wash. DC). 243:916-922

39. Deretic, V., R. Dikshit, W. M. Konyecsni, A. M. Chakrabarty, and T. K. Misra. 1989. The algR gene which regulates mucoidy in Pseudomonas aeruginosa belong to a class of environmentally responsive genes. J. Bacteriol. 171:12781283.

40. Storey, D. G., D. W. Frank, M. A. Farinha, A. M. Kropinski, and B. H. Iglewski. 1990. Multiple promoters control the regulation of the Pseudomonas aeruginosa regA gene. Mol. Microbiol. 4:499-503.

41. Deretic, V, and W. M. Konyecsni. 1989. Control of mucoidy in Pseudomonas aeruginosa: transcriptional regulation of $a l g R$ and identification of the second regulatory gene algQ. J. Bacteriol. 171:3680-3688.

42. DeVault, J. D., A. Berry, T. K. Misra, A. Darzins, and A. M. Chakrabarty 1989. Environmental sensory signals and microbial pathogenesis: Pseudomonas aeruginosa infection in cystic fibrosis. Bio/Technology. 7:352-357.

43. Kimbara, K., and A. M. Chakrabarty. 1989. Control of alginate synthesis in Pseudomonas aeruginosa regulation of the algRl gene. Biochem. Biophys. Res. Commun. 164:601-608.

44. Kato, J., L. Chu, K. Kitano, J. D. DeVault, K. Kimbara, A. M. Chakrabarty, and T. K. Misra 1989. Nucleotide sequence of a regulatory region controlling alginate synthesis in Pseudomonas aeruginosa characterization of the algR2 gene. Gene. 84:31-38.

45. Schauer, R., and J. F. G. Vliegenthart. 1982. In Sialic Acids: Chemistry, Metabolism, and Function, R. Schauer, editor. Springer-Verlag, Inc New York. 1-3.

46. Bouwstra, J. B., C. M. Deyl, and J. F. G. Vliegenthart. 1987. Purification and kinetic properties of sialidase from Clostridium perfringens. Biol. Chem. Hoppe-Seyler. 368:269-275.

47. Ada, G. L., E. L. French, and P. E. Lind. 1961. Purification and properties of neuraminidase from Vibrio cholerae. J. Gen. Microbiol. 24:409-421.

48. Corfield, A. P, R. W. Veh, M. Wember, J. C. Michalski, and R. Schauer 1981. The release of $N$-acetyl- and $N$-glycolloyl-neuraminic acid from soluble complex carbohydrates and erythrocytes by bacterial, viral, and mammalian sialidases. Biochem. J. 197:293-299.

49. Corfield A. H. Higa, J. C. Paulsen, and R. Schauer. 1983. The specificity of viral and bacterial sialidases for $\alpha(2-3)$ - and $\alpha(2-6)$-linked sialic acids in glycoproteins. Biochim. Biophys. Acta. 744:121-126.

50. Paranchych, W., R. T. Irvin, R. S. Hodges, and D. E. Woods. 1991. Functional analysis of synthetic analogues of bacterial adhesins specific for mammalian glycoconjugate receptors. Pediatr. Pulmonol. Suppl. 6:134-135.

51. Baker, N. R., V. Minor, C. Deal, M. S. Shahrabadi, D. A. Simpson, and D. E. Woods. Pseudomonas aeruginosa exoenzyme $\mathrm{S}$ is an adhesin. Infect. Immun. 59:2859-2863.

52. Sajian, U., J. Reisman, P. Doig, R. T. Irvin, G. Forstner, and J. Forstner. 1992. Binding of nonmucoid Pseudomonas aeruginosa to normal human intestinal mucin and respiratory mucin from patients with cystic fibrosis. J. Clin. Invest. 89:657-665.

53. Wozniak, D. J., and D. E. Ohman. 1991. Pseudomonas aeruginosa AlgB, a two-component response regulator of the $\mathrm{NtrC}$ family, is required for algD transcription. J. Bacteriol. 173:1406-1413.

54. Knowles, M. R., N. L. Church, W. W. Waltner, J. R. Yankaskas, P. Gilligan, M. King, L. J. Edwards, R. W. Helms, and R. C. Boucher. 1990. A pilot study of aerosolized amiloride. $N$. Engl. J. Med. 322:1189-1194. 